\title{
Erratum to: Production and financial linkages in inter-firm networks: structural variety, risk-sharing and resilience
}

\section{Giulio Cainelli • Sandro Montresor • Giuseppe Vittucci Marzetti}

Published online: 6 October 2012

(C) Springer-Verlag Berlin Heidelberg 2012

\section{Erratum to: J Evol Econ \\ DOI 10.1007/s00191-012-0280-6}

The original version of this article unfortunately misses the following disclaimer, which has to be considered as part of its acknowledgments: The views expressed are purely those of the authors and may not in any circumstances be regarded as stating an official position of the European Commission.

The online version of the original article can be found at http://dx.doi.org/10.1007/s00191-012-0280-6.

G. Cainelli

CERIS-CNR, Milan, Italy

G. Cainelli

Department of Economics and Management "Marco Fanno", University of Padua, via del Santo 33, 35122 Padua, Italy

e-mail: giulio.cainelli@unipd.it

S. Montresor

JRC-IPTS European Commission, Seville, Spain

S. Montresor $(\varangle)$

Department of Economics, University of Bologna,

Bologna, Italy

e-mail: sandro.montresor@unibo.it

G. Vittucci Marzetti

Department of Sociology and Social Research, University of Milano-Bicocca, via Bicocca degli Arcimboldi 8, 20126 Milan, Italy

e-mail: giuseppe.vittucci@unimib.it 